Pak. j. sci. ind. res. Ser. A: phys. sci. 2016 59(3) 121-125

\title{
Effect of Storage on Physicochemical Characteristics of Some Selected Vegetable Oils
}

\author{
Zahida Karima*, Farhat Ikram ${ }^{a}$, Aneela Karim ${ }^{a b}$ and Khalid Mohammed Khan ${ }^{b}$ \\ ${ }^{a}$ Department of Chemistry, University of Karachi, Karachi 75270, Pakistan \\ ${ }^{\mathbf{b}}$ HEJ Research Institute of Chemistry, International Centre for Chemical and Biological Sciences, \\ University of Karachi, Karachi 75270, Pakistan
}

(received April 21, 2015; revised August 20, 2015; accepted August 21, 2015)

\begin{abstract}
The quality of fats and oils is analysed by several physical and chemical parameters that are dependent on the source of oil as well as processing and storage conditions. In the present study, refractive index, peroxide, saponification, and acid values of different branded and unbranded vegetable oils were determined. Storage stability of oil samples were investigated and fastest deterioration was observed when samples were exposed to day light. UV radiations also caused oxidative damage, as indicated by the increased peroxide values for the samples exposed to UV radiations for 0,5 and $10 \mathrm{~min}$, respectively. Direct sunlight and UV rays are particularly found responsible for the degradation of oil quality.
\end{abstract}

Keywords: peroxide value, refractive index, saponification value, storage stability, UV radiations, vegetable oil

\section{Introduction}

Vegetable oils and fats are tri-esters of a glycerol molecule with three molecules of fatty acid, where the fatty acids contain long chains of carbon (8-24 units long) (Rubalya et al., 2013; Pardauil et al., 2011; Vecchio et al., 2008; Pasca and Dadarlat, 2007; Conceicao et al., 2007). These tri-esters have the basic nutritional function of supplying calories (Rostocki et al., 2013). They also contribute to the palatability of foods, act as vehicles for fat soluble vitamins, such as A, D, E and $\mathrm{K}$, and are sources of essential fatty acids, such as linoleic, linolenic, and arachidonic acid (Pardauil et al., 2011; Fuentes et al., 2010; Castro et al., 2004). Oils that are more unsaturated are oxidized more rapidly than less unsaturated oils. Oxidation of oil produces rancid flavours and the formation of oxidation products can also decrease its nutritional quality (Morales et al., 2014; Ahmed et al., 2011; Muik et al., 2005 ). Reactive oxygen species which have been generated due to lipid oxidation may cause several disorders like inflammation, carcinogenesis, early aging and cardiovascular diseases (Raza et al., 2009). Several factors like oil processing, fatty acid composition of oil, free fatty acids, transition metals, the concentration and type of oxygen, monoand diacylglycerols, energy of heat or light, peroxides and antioxidants influences oxidation of oil (Choe and Min, 2006).

*Author for correspondence; E-mail: zkareem@uok.edu.pk
Improper storage conditions of oil may cause nutritional quality deterioration of food. Therefore, in the present study, some physicochemical parameters that determine the quality of oil are used to study the oxidative deterioration of different vegetable oils stored under various conditions i.e.darkness, room temperature, refrigeration and sunlight.

\section{Materials and Methods}

Different branded and unbranded cooking oils were purchased from departmental stores and from local grocery stores and used in the present study (Table 1). The physicochemical properties of oil samples like refractive index, peroxide acid, and saponification values were measured.

The refractive index was measured through Carl Zeiss Abbe Refractometer according to AOAC (2003) Official Method at $25{ }^{\circ} \mathrm{C}$. For the determination of peroxide value, in accurately weighed oil sample, $\mathrm{CH}_{3} \mathrm{COOH}-$ $\mathrm{CHCl}_{3}(60: 40)$ along with $1 \mathrm{~g}$ of $\mathrm{KI}$ and $30 \mathrm{~mL}$ of freshly boiled water were added and kept in dark for $10 \mathrm{~min}$. Titration was performed using $0.01 \mathrm{~N}$ standard sodium thiosulphate and using starch as an indicator, until colour of the solution discharged. For the estimation of acid value, $10 \mathrm{~mL}$ of ethanol and $10 \mathrm{~mL}$ of hexane were taken into a conical flask and titrated against standard $0.01 \mathrm{~N} \mathrm{KOH}$ using phenolphthalein indicator till the appearance of faint pink colour. $1 \mathrm{~g}$ of oil sample was added into the same flask and after adding 
phenolphthalein, contents of the flask were titrated against standard $\mathrm{KOH}$ until faint pink colour obtained. For saponification value, in $1 \mathrm{~g}$ of oil sample, $15 \mathrm{~mL}$ of $1 \mathrm{~N}$ alcoholic $\mathrm{KOH}$ were added and it was refluxed on water bath for $45 \mathrm{~min}$. After adding phenolphthalein indicator, excess potassium hydroxide was titrated with $0.5 \mathrm{~N}$ oxalic acid until the colour changed from pink to colourless. Blank was also treated in the same way.

For oxidative stability determination, oil samples were transferred to transparent glass vials $(5 \mathrm{~mL}$ of $2 \mathrm{~cm}$ in diameter). The vials were closed and subjected to different storage conditions: (i) at room temperature in darkness i.e., control, (ii) at room temperature with exposure to daylight (iii), at $12{ }^{\circ} \mathrm{C}$ in refrigerator, (iv) direct exposure to sunlight. Samples were stored for 14 days in each storage condition and their chemical properties i.e. peroxide, acid and saponification values were noted.

\section{Results and Discussion}

Several parameters have been used to characterize the edibility of vegetable oil, such as refractive index, peroxide acid and saponification values. These parameters determine the quality of oil and are routinely used for quality control to ensure provision of appropriate quality of oil for consumption/ related purposes.

Refractive index. The refractive index (RI) of fats and oils is sensitive to their composition. In fats, RI increases with increasing chain length of fatty acids in the triglycerides or with increasing unsaturation. This makes it an excellent spot test for uniformity of compositions of oils and fats (Fakhri and Qadir, 2011). Values of refractive index for different oils generally vary between 1.447 and 1.482 (Shahidi, 2005). In the present study, refractive index values of branded and unbranded oil samples were found in the range of 1.4720-1.4745 and 1.4609-1.4744, respectively (Table 1). Low refractive index of unbranded coconut oil (i.e., 1.4609) is possibly due to low average molecular weight of its fatty acid.

Peroxide value. Peroxide value (PV, meq $\mathrm{O}_{2} / \mathrm{kg}$ oil) is a measure of oxidative rancidity and a guide to edible oil quality. Peroxide value is one of the most commonly used quality indices during edible oil production, storage and marketing (Nouros et al., 1999). Fresh oils have peroxide values less than 10 meq $\mathrm{O}_{2} / \mathrm{kg}$ and it is considered rancid when the peroxide value is about 10 meq $\mathrm{O}_{2} / \mathrm{kg}$ (Halvorsen and Blomhoff, 2011).
Table 1. Refractive index value of branded and unbranded oil samples

\begin{tabular}{ll}
\hline \hline Oil samples & Refractive index \\
\hline Unbranded & \\
Canola (CN) & 1.4732 \\
Cotton seed (CS) & 1.4673 \\
Mustard (MT) & 1.4744 \\
Coconut (CC) & 1.4609 \\
Sesame (SE) & 1.4714 \\
Sunflower (SF) & 1.4739 \\
Soybean (SB) & 1.4716 \\
Branded & \\
I (TU) & 1.4730 \\
II (MZ) & 1.4725 \\
III (SM) & 1.4739 \\
IV (DD) & 1.4735 \\
V (CD) & 1.4720 \\
VI (KS) & 1.4721 \\
VII (HB) & 1.4736 \\
VIII (EV) & 1.4745 \\
IX (SS) & 1.4742 \\
X (CR) & 1.4739 \\
\hline \hline
\end{tabular}

When subjected to different storage conditions, branded as well as unbranded cooking oil samples showed change in the peroxide values. The effects of various treatments on peroxide values of various oil samples are depicted in Fig 1. Peroxide value of branded oil samples when stored in dark are found in the range of 3.584-8.957 meq $\mathrm{O}_{2} / \mathrm{kg}$. When the samples were stored at room temperature, refrigerated or exposed to sunlight, a significant shift in peroxide values was noticed.

Effect of different storage conditions on peroxide values of unbranded oil samples are shown in Fig. 2. As the

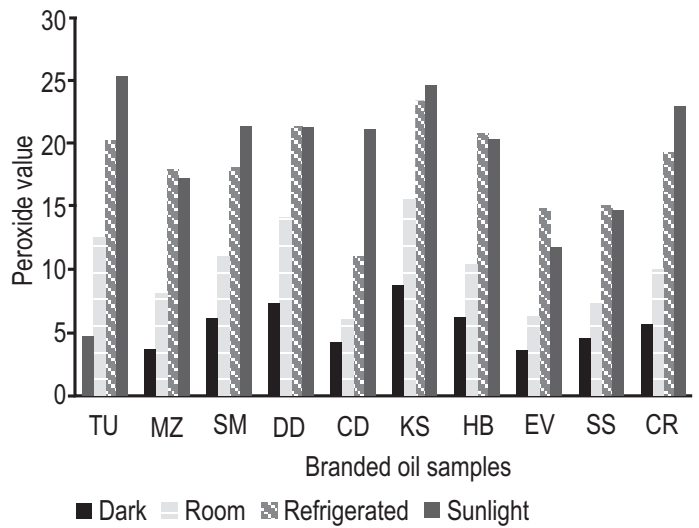

Fig. 1. Peroxide value (meq $\mathrm{O}_{2} / \mathrm{kg}$ ) of branded oil samples. 
fatty acid composition of canola, sunflower, soybean oils etc. varied, their degree of susceptibility to different storage conditions is also expected to be different. Peroxide value of mustard oil was found to be more easily affected by change in storage conditions, which may be due to its less resistance to lipolytic hydrolysis and oxidative deterioration.

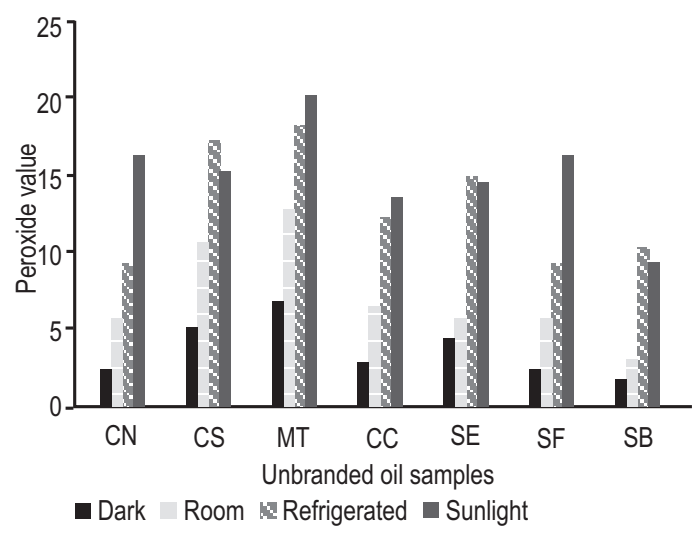

Fig. 2. Peroxide value (meq $\mathrm{O}_{2} / \mathrm{kg}$ ) of unbranded oil samples.

Results of this study indicated that the peroxide values of branded and unbranded oil samples were lower than 10 meq $\mathrm{O}_{2} / \mathrm{kg}$ when oil samples were stored in dark and higher when stored at low temperature or when exposed to direct sunlight.

The solubility of oxygen in liquids is favourable at lower temperatures, which in turn may negatively affect the oil stability (Turek et al., 2012, Bernhard and Marr 1960). Therefore, peroxyl radicals as well as hydro peroxides have been reported to be the most frequent compounds upon oxidation of edible oils at lower temperatures (Turek and stinzing et al., 2013). Turek et al. (2012) also reported high peroxide values for lavender and thyme oil stored in the refrigerator at $5^{\circ} \mathrm{C}$.

When oils are exposed to sunlight their $\pi$-bonds contents become photoxidized (Fekarurhobo et al., 2009). In the presence of sunlight, oxygen reacts with the double bonds of fatty acids to form peroxides and/or free radicals (Frankel, 1991). Photo oxidation with singlet oxygen is not even controlled by the antioxidants commonly used to inhibit autoxidation (Kiritsakis and Dugan, 1985). Duration of exposure to UV light also caused significant influence on the peroxide values of different branded and unbranded oil samples (Fig. 3).

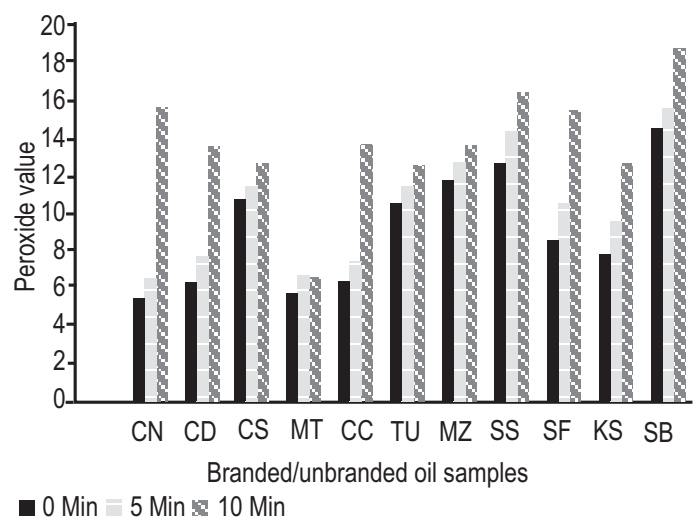

Fig. 3. Effect of UV light on peroxide value (meq $\mathrm{O}_{2} / \mathrm{kg}$ ) of branded and unbranded oil samples.

Ultraviolet (UV) light is considered to accelerate autoxidation process by triggering the hydrocarbon abstraction which thus results in the formation of alkyl radicals (Turek et al., 2012; Choe and Min, 2006; AOCS, 2003).

Acid value. Acid value determines the presence of corrosive free fatty acids (FFAs) and oxidation products. Fatty acids are usually found in the triglyceride form, however, during processing the fatty acids may get hydrolyzed into FFAs. Acceptable levels of FFAs for all oil samples should be below $0.6 \mathrm{mg} \mathrm{KOH} / \mathrm{g}$ (AOCS, 2003).

Branded and unbranded cooking oil samples, when stored under different conditions showed shift in the acid values (Fig. 4-5). However, direct exposure to sunlight caused decomposition of glyceride in the oil and thus resulted in a most significant influence on the acid value of the oil samples. Results are in agreement with those of Patterson (1992) showing that the free fatty acids of oil samples increased during storage and samples stored under light showed a very significant difference over those stored in the dark (Kucuk and Canel, 2005).

Saponification value. Saponification value is the number of $\mathrm{mg}$ of $\mathrm{KOH}$ that is required to saponify/ neutralize the fatty acids present as acyl glycerol in $1 \mathrm{~g}$ of fat. Three molecules of $\mathrm{KOH}$ are consumed for saponification of each molecule of triacylglycerol, irrespective of the chain length of a fatty acid. Each gram of oil containing more amount of triacylglycerol will therefore require much more $\mathrm{KOH}$ and hence, its 


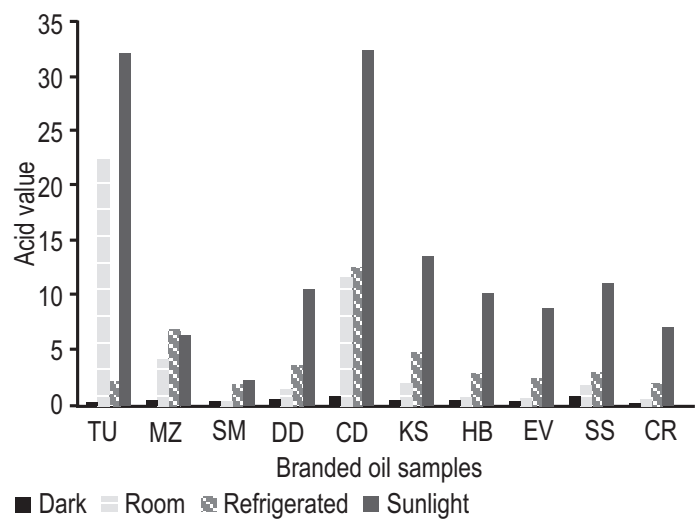

Fig. 4. Acid value (mg KOH/g) of branded oil samples

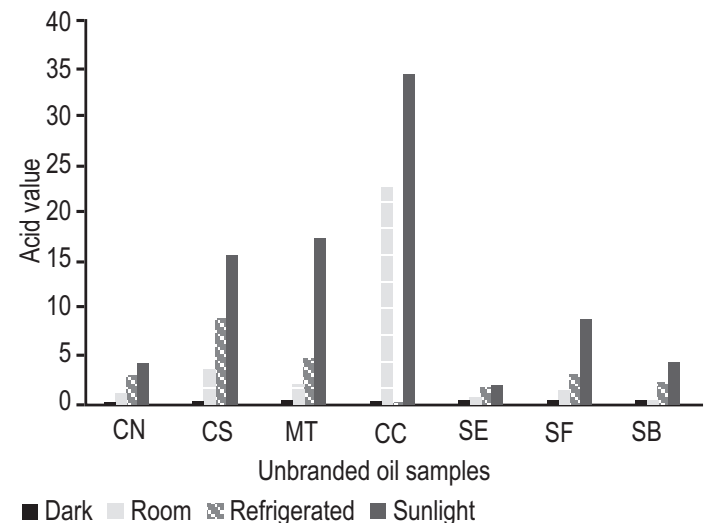

Fig. 5. Acid value (mg KOH/g) of unbranded oil samples.

saponification value will be higher. The saponification value is thus an indication of average molecular weight of the fatty acid in an acylglyceride (Akhtar et al., 2009). Figure 6 and 7 present the saponification of various branded and unbranded oils when stored under different conditions. Low saponification value of branded IV and cottonseed (unbranded) oil indicates the presence of high molecular weight fatty acids. Whereas, coconut oil consists of glyceride of fatty acids with low molecular weight and hence, has high saponification value. Saponification value of the branded and unbranded oil is also found to be influenced by the storage conditions.

Exposure to direct sunlight and UV rays are particularly found responsible for the degradation of oil quality. Great care therefore, should be taken during the oil storage in order to prevent the development of rancidity. The experimental results obtained in this work are preliminary

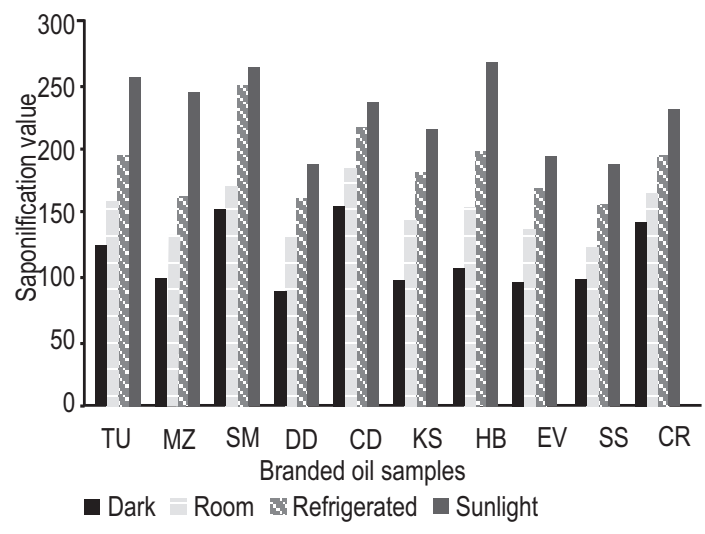

Fig. 6. Saponification value of branded oil samples.

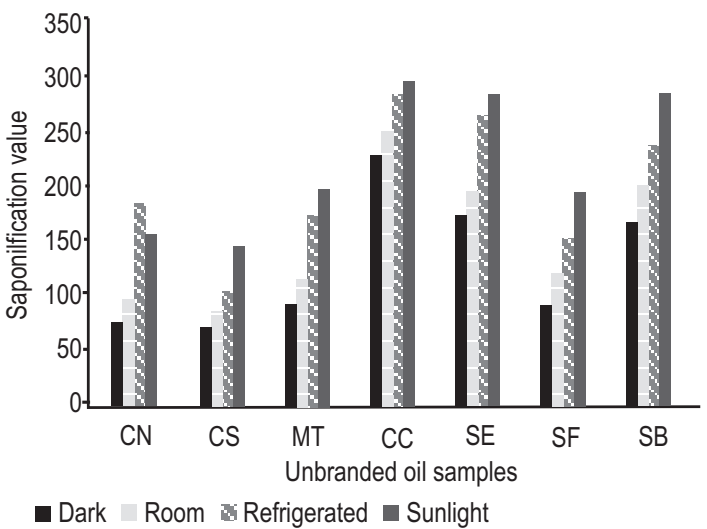

Fig. 7. Saponification value of unbranded oil samples.

and further research is required to use advanced analytical approaches and instrumentation to gain more understanding of the possible oxidation processes at various storage conditions and strategies to avoid them.

\section{Acknowledgement}

The Dean Faculty of Science, University of Karachi is gratefully acknowledged for providing research funding for this project.

\section{References}

Akhtar, N., Ahmad, M., Adnan, Q., Ahmed, M., Farzana, K. 2009. Rheological studies and characterization of different oils. Journal of the Chemical Society of Pakistan, 31: 201-206.

Ahmed, T., Atta, S., Sohail, M., Khan, A. R., Akhtar, S. 2011. Effect of fluorescent light on quality and 
stability of edible fats and oils. Journal of the Chemical Society of Pakistan, 33: 233-237.

AOCS, 2003. Official Method Cd 8-53. American Oil Chemists Society, Champaign, IL, USA.

Bernhard, R.A., Marr, A.G. 1960. The oxidation of terpenes. I. mechanism and reaction products of D-Limonene autoxidation. Journal of Food Science, 25: $517-530$.

Castro, H.F., Mendes, A.A., Santos, J.C. 2004. Modification of oils and fats by biotransformation. Quimica Nova, 27: 146-156.

Choe, E., Min, D. B. 2006. Mechanisms and factors for edible oil oxidation. Comprehensive Reviews in Food Science and Food Safety, 5: 169-186.

Conceicao, M. M., Fernandes, Jr. V. J., Bezerra, A. F., Silva, M. C. D., Santos, I. M. G., Silva, F. C., Souza, A. G. 2007. Dynamic kinetic calculation of castor oil biodiesel. Journal of Thermal Analysis and Calorimetry, 87: 865-869.

Fakhri, N.A., Qadir, H.K. 2011. Studies on various physico-chemical characteristics of some vegetable oils. Journal of Environmental Science and Engineering, 5: 844-849.

Fekarurhobo, G. K., Obomanu, F. G., Maduleosi, J. 2009. Effects of short-term exposure to sunlight on the quality of some edible vegetable oils. Research Journal of Applied Sciences, 4: 152-156.

Frankel, E. N. 1991. Recent advances in lipid oxidation. Journal of the Science of Food and Agriculture, 54: 495-511.

Fuentes, J.A., Camey-Ortiz, G., Hernandez-Medel, M.R., Mendoza, F.P., Bazua, C.D. 2010. Composition, phase behavior and thermal stability of natural edible fat from rambutan (Nephelium lappaceum L.) seed. Bioresource Technology, 101: 799-803.

Halvorsen, B.L., Blomhoff, R. 2011. Determination of lipid oxidation products in vegetable oils and marine omega-3 supplements. Food \& Nutrition Research, 55: 5792 .

Kiritsakis, A., Dugan, L.R. 1985. Studies in photo oxidation of olive oil. Journal of the American Oil Chemists, Society, 62: 892-896.

Kucuk, M., Caner, C. 2005. Effect of packaging materials and storage conditions on sunflower oil quality. Journal of Food Lipids, 12: 222-231.

Morales, A., Marmesat, S., Ruiz-Mendez, M. V., Marquez-Ruiz, G., Velasco, J. 2014. Formation of oxidation products in edible vegetable oils analyzed as FAME derivatives by HPLC-UV-ELSD. Food Research International, 62: 1080-1086.
Muik, B., Lendl, B., Molina-Diaz, A., Ayora-Canada, M. J. 2005. Direct monitoring of lipid oxidation in edible oils by Fourier transform Raman spectroscopy. Chemistry and Physics of Lipids, 134: 173-182.

Nouros, P. G., Georgiou, C. A., Polissiou, M. G. 1999. Direct parallel flow injection multichannel spectrophotometric determination of olive oil peroxide value. Analytica Chimica Acta, 389: 239-245.

Pardauil, J. J., Souza, L. K., Molfetta, F. A., Zamian, J. R., Rocha Filho, G. N., da Costa, C.E. 2011. Determination of the oxidative stability by DSC of vegetable oils from the Amazonian area. Bioresource Technology, 102: 5873-5877.

Pasca, A., Dadarlat, D. 2007. Study of edible oils adulteration by ultrasonic attenuation. Romanian Journal of Physics, 52: 641-644.

Patterson, H.B.W. 1992. Bleaching and Purifying Fats and Oils, Theory and Practice, AOCS Press, Champaign IL., American Oil Chemists, Society Champaign, Illinois, USA.

Raza, S.A., Rashid, A., Qureshi, F.A., Asim, M.F., Najaf, S., William, J. 2009. Analytical investigation of oxidative deterioration of sunflower oil stored under different conditions. Electronic Journal of Environmental, Agricultural and Food Chemistry, 8: 1043-1051.

Rostocki, A.J., Tarakowski,R.,Kielczynski, P., Szalewski, M., Balcerzak, A., Ptasznik, S. 2013. The ultrasonic investigation of phase transition in olive oil up to $0.7 \mathrm{GPa}$. Journal of the American Oil Chemists' Society, 90: 813-818.

Rubalya, V. S., Chandiramauli, R., Neelamegam, P. 2013. Detection of adulteration in olive oil using rheological and ultrasonic parameters. International Food Research Journal, 20: 3197-3202.

Shahidi, F. 2005. Quality Assurance of Fats and oils, In: Bailey's Industrial Oil and Fat Products, 3616 pp., $6^{\text {th }}$ edition, John Wiley and Sons, Inc., USA.

Turek, C., Stintzing, F. C. 2013. Stability of essential oils. Comprehensive Reviews in Food Science and Food Safety, 12: 40-53.

Turek, C., Kirschmann, N., Stintzing, F.C. 2012. Quality monitoring of selected essential oils upon storage at different temperature regimes. Journal of Medicinal and Spice Plants, 17: 73-79.

Vecchio, S., Campanella, L., Nuccilli, A., Tomassetti, M. 2008. Kinetic study of thermal breakdown of triglycerides contained in extra-virgin olive oil. Journal of Thermal Analysis and Calorimetry, 91: 51-56. 